Siti Zulaili Zulkepli, MD

Salina Husain, MBBS, MS(ORL-HNS)

Balwant Singh Gendeh, MBBS, MS(ORL-HNS)

Department of Otorhinolaryngology Head and Neck Surgery

Universiti Kebangsaan Malaysia Medical Center

Correspondence: Dr Salina Husain

Department of Otorhinolaryngology

Head and Neck Surgery

Universiti Kebangsaan Malaysia Medical Center

Jalan Yaacob Latif, 56000

Kuala Lumpur, Malaysia

Phone: (+603) 91455555

Fax: (+603E) 91456675

Email:drsalina_h@yahoo.com

Reprints will not be available from the authors.

The authors declared that this represents original material that is not being considered for publication or has not been published or accepted for publication elsewhere, in full or in part, in print or electronic media; that the manuscript has been read and approved by all the authors, that the requirements for authorship have been met by each author, and that each author believes that the manuscript represents honest work.

Disclosures: The authors signed disclosures that there are no financial or other (including personal) relationships, intellectual passion, political or religious beliefs, and institutional affiliations that might lead to a conflict of interest.

\section{Respiratory Epithelial Adenomatoid Hamartoma of the Nasal Septum}

\begin{abstract}
Objective: Hamartomas are relatively uncommon, non-neoplastic malformations indigenous to the involved anatomic site. Respiratory epithelial adenomatoid hamartoma (REAH) is a subset of hamartoma characterized by prominent glandular proliferation lined by ciliated epithelium originating from the surface epithelium. Their location in the nasal cavity is rare and when present, mostly associated with the posterior nasal septum. We present such a case arising from the anterior nasal septum.
\end{abstract}

\section{Methods:}

Design: Case report

Setting: Tertiary University Referral Center

Patient: One

Results: A 32-year-old lady who presented with a long-standing nasal block was found to have a broad-based nasal mass arising from the left anterior nasal septum. The lesion was histologically diagnosed as respiratory epithelial adenomatoid hamartoma following surgical excision.

Conclusion: Respiratory epithelial adenomatoid hamartoma although rare must be taken into consideration in the differential diagnosis of nasal lesions.

Keywords: respiratory epithelial adenomatoid hamartoma; anterior nasal septum; nasal block

Hamartomas are benign, non-neoplastic malformations or inborn errors of tissue development that result from excessive proliferation of otherwise normal local tissue components. Hamartomas can occur anywhere in the body, including lung, liver, spleen and kidney but involvement of the head and neck and in particular, the nasal cavity and paranasal sinus is relatively uncommon. ${ }^{1}$ 
Hamartomas can be further classified into mesenchymal and epithelial subtypes according to predominant element on histopathologic examination. A particular subset of epithelial subtype known as respiratory epithelial adenomatoid hamartoma (REAH) was first described in 1995 by Wenig and Heffner in a series of 31 cases from the files of the Otolaryngic Tumor Registry at the Armed Forces Institute of Pathology. ${ }^{2}$ Until now, there is limited literature regarding REAH and most of the articles have been published as case reports.

The challenge of this lesion is not to over-diagnose it as malignant as it can be treated with a simple excision. We present a case report of a 32-year-old lady with REAH localized in the left anterior nasal septum.

\section{CASE REPORT}

A 32-year-old Chinese lady presented with a long-standing unilateral nasal blockage associated with nasal discharge and hyposmia. There was no history of facial pain, epistaxis or eye symptoms. She was otherwise healthy with no known co-morbidities.

On physical examination, there was a broad-based $2 \times 1.5 \mathrm{~cm}$ swelling originating from the left anterior nasal septum. It was firm and non-tender on palpation. The overlying mucosa appeared normal and smooth.

The patient underwent an excisional biopsy under general anesthesia. Histological evaluation revealed a polypoidal mass lined by respiratory epithelium and contained glandular and florid proliferation of tubular glands lined by ciliated, respiratory-type epithelium and goblet cells. The stroma was mostly oedematous with areas of hyalinization and a focus of chronic inflammatory infiltrate. No atypia or increased mitotic figures were observed. These findings were consistent with the diagnosis of respiratory epithelial adenomatoid hamartoma (REAH). (Figure 1 and 2)

Post-operatively, the excisional biopsy site re-epithelialised and healed well. There was no recurrence observed after four months of follow up.

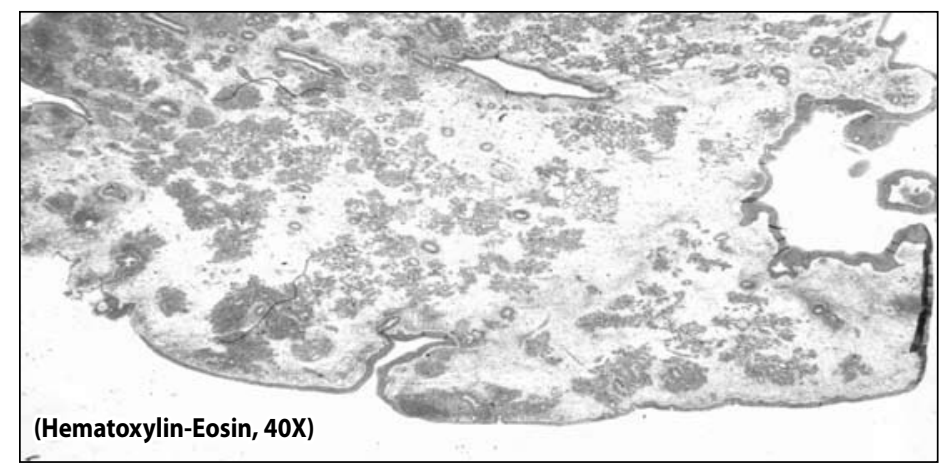

Figure 1. Low-power photomicrograph of a REAH shows glandular and tubular proliferation lined by respiratory type epithelium $(\mathrm{H} \& \mathrm{E}, 40 \mathrm{x})$.

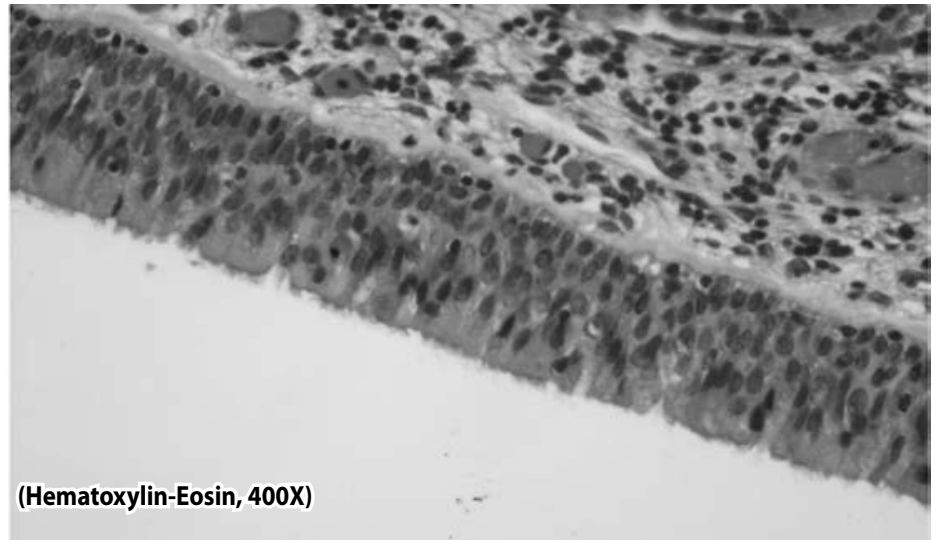

Figure 2. High power photomicrograph of polypoidal mass lined by respiratory type epithelium (H\&E 400x).

\section{DISCUSSION}

REAH is a benign lesion predominantly affecting adult men with male to female ratio of about 7:1 and associates with tobacco use. ${ }^{2}$ Prior to 1995 , only 13 cases involving the head and neck region other than Wenig and Heffner have been reported. To date, about 60 cases have been published as case reports, confirming the rare nature of this proliferation. In the head and neck region, it commonly occurs in the nasal cavity, paranasal sinuses and nasopharynx. Their localization in the nasal cavity is mostly described in the posterior nasal septum although lesions arising from the lateral nasal wall have also been reported. ${ }^{1,3}$

The lesion in our patient was found to arise from the anterior part of nasal septum, a few millimeters behind the mucocutaneous junction. Involvement of the anterior part of the nasal septum is an unusual location and to our knowledge only one such case has been reported in English literature. ${ }^{4}$ Other areas in the sinonasal tract where the lesion has been documented are maxillary sinus, ethmoid sinus and nasopharynx. ${ }^{5-7}$

The etiology of the lesion is unclear. REAH of the nasal cavity has been described in association with nasal polyposis that supports the hypothesis that inflammation could be one of the inducing factors. ${ }^{8}$

Commonly described presenting complaints were nasal obstruction, nasal stuffiness, epistaxis, rhinorrhea, chronic recurrent sinusitis, facial pain, proptosis and hyposmia. ${ }^{2}{ }^{4}$ This lady had similar presenting complaints of nasal block, discharge and hyposmia.

The histologic picture is usually characterized by the presence of a glandular proliferation lined by ciliated respiratory epithelium, originating from the surface respiratory epithelium. The glands are typically round to oval in shape and small to medium in size with prominent dilation. Stromal tissue separates the gland and no destructive growth was noted. ${ }^{1}$ 


\section{CASE REPORTS}

There is no specific feature on imaging studies. REAH can mimick any benign sinonasal tumor with the most common finding of REAH being an opacification of the affected sinus and some connection to the nasal septum. Calcification may be visualized within the lesion but bone erosion and intracranial involvement are uncommon. ${ }^{4}$

It is important to consider this diagnosis as the definitive treatment for REAH is simple surgical excision. Excision is an adequate treatment with excellent prognosis. REAH does not progress and does not regress spontaneously. Following surgical excision there was no reported recurrence in the literature so far. ${ }^{2,8}$

Respiratory epithelial adenomatoid hamartoma is a rare lesion in the head and neck region. One should be familiar with this entity and it should be considered in the differential diagnosis of nasal lesions. Diagnosis misinterpretation only results in unnecessary surgical intervention.

1. Nair S, Bahal A, Gupta ML, Lkhtakia R. REAH: unusual case of unilateral nasal blockage. MJAFI. 2008 Jul; 64(3): 280-281.

2. Wenig BM, Heffner DK. Respiratory epithelial adenomatoid hamartomas of the sinonasal tract and nasopharynx: a clinicopathologic study of 31 cases. Ann Otol Rhinol Laryngol. 1995 Aug 104(8): 639-645.

3. Cao ZW, Gu ZW, Yang J, Jin MZ. Respiratory epithelial adenomatoid hamartoma of bilateral olfactory clefts associated with nasal polyposis: 3 case report and literature review. Auris Nasus Larynx. 2010 Jun; 37(3): 352-356.

4. Gajda M, Zagolski O, Jasztal A, Lis GJ, Pyka-Fosciak G, Litwin JA. Respiratory epithelial adenomatoid hamartoma of the anterior nasal septum is a rare localization of an unusual tumour in a child: a case report. Cases J. 2009 Sep; 16(2): 8151-8152.

5. Mortuaire G, Pasquesoone X, Leroy X, Chevalier D. Respiratory epithelial adenomatoid hamartomas of the sinonasal tract. Eur Arch Otorhinolaryngol 2007 Nov; 264(4): 451-453

6. Starska K, Lukomski M, Ratynska M. Rare case of respiratory epithelial adenomatoid hamartoma of the nasal cavity, maxillary sinus and ethmoid sinus: a clinicopathologic study. Otolaryngol Pol 2005; 59(3): 421-424

7. Kessler HP, Unterman B. Respiratory epithelial adenomatoid hamartoma of the maxillary sinus presenting as a periapical radiolucency: a case report and review of literature. Oral Surg Ora Med Oral Pathol Oral Radiol Endod 2004 May; 97(5): 607-612

8. Delbrouk C, Aguilar SF, Choufani G, Hassid S. Respiratory epithelial adenomatoid hamartoma associated with nasal polyposis. Am J Otolaryngol. 2004 Jul; 25(4): 282-284. 